\title{
Peran Project Owner dalam Menjalankan Agile Project Management (Studi Kasus: PT. XYZ)
}

\author{
The Role of the Project Owner to Run the Agile Project Management (Case Study: \\ PT. XYZ)
}

\author{
Fernanda Rachmadini \\ Master Program Student, Universitas Mercubuana Jl. Menteng Raya No.29, Kel.Kebon Sirih, Kec.Menteng, Jakarta \\ e-mail: rachmadini.fernanda@gmail.com \\ Sugeng Santoso \\ Lecturer, Universitas Mecubuana, Jl. Menteng Raya No.29, Kel.Kebon Sirih, Kec.Menteng, Jakarta \\ e-mail: sugeng.santoso@mercubuana.ac.id
}

\begin{abstract}
Agile project management methodologies provide the means to respond to highly dynamic customer needs. One of the agile project management frameworks is scrum. Scrum is shaped in 3 important roles by project owner, scrum master, and development team. The research objective was to determine the roles and responsibilities of the project owner when run several projects at PT. XYZ using the agile project management methodology scrum framework. The research method used is descriptive qualitative, with the investigative method adopted is a single case study, namely the company PT. XYZ which is engaged in IT with several application development projects. The results obtained from the interview are that the role of the project owner must understand the needs desired by customers by being sensitive to customer needs that highlight quality and uncertain changes, besides understanding the scrum team in delivering product services desired by customers in order to provide maximum quality and acceptance by the customer. In addition, the project owner must carry out the responsibilities such as explaining the SoW and the objectives to be achieved in the project, preparing a budget for the project, allocating of development teams who will work on the product, determining the priority of the product backlog and the sprint that will be executed, monitoring each stage sprints that are being worked on by the developer team, holding daily meetings for a maximum of 15 minutes with the scrum team, arranging and holding meetings with customers and the scrum team for each sprint that has been completed, and collaborating with the scrum team to discuss any changes desired by customers.
\end{abstract}

Keywords: Agile project management, project owner, scrum framework.

\begin{abstract}
ABSTRAK
Metodologi manajemen proyek tangkas menyediakan sarana untuk menanggapi kebutuhan pelanggan yang sangat dinamis. Salah satu kerangka kerja manajemen proyek tangkas adalah scrum. Scrum dibentuk dalam 3 peran penting oleh pemilik proyek, master scrum, dan tim pengembangan. Tujuan penelitian adalah untuk mengetahui peran dan tanggung jawab pemilik proyek dalam menjalankan beberapa proyek di PT. XYZ menggunakan kerangka kerja scrum metodologi manajemen proyek tangkas. Metode penelitian yang digunakan adalah deskriptif kualitatif, dengan metode investigasi yang diadopsi adalah studi kasus tunggal yaitu perusahaan PT. XYZ yang bergerak di bidang IT dengan beberapa proyek pengembangan aplikasi. Hasil yang diperoleh dari wawancara adalah bahwa peran pemilik proyek harus memahami kebutuhan yang diinginkan oleh pelanggan dengan peka terhadap kebutuhan pelanggan yang menonjolkan kualitas dan perubahan yang tidak pasti, selain itu memahami tim scrum dalam memberikan layanan produk yang diinginkan pelanggan agar dapat memberikan kualitas dan penerimaan maksimal oleh pelanggan. Selain itu, pemilik proyek harus menjalankan tanggung jawab seperti menjelaskan SoW dan tujuan yang ingin dicapai dalam proyek, menyiapkan anggaran proyek, mengalokasikan tim pengembang yang akan mengerjakan produk, menentukan prioritas product backlog dan sprint yang akan dijalankan, memantau setiap tahapan sprint yang sedang dikerjakan oleh tim pengembangan, mengadakan pertemuan harian maksimal 15 menit dengan tim scrum, mengatur dan mengadakan pertemuan dengan pelanggan dan tim scrum untuk setiap sprint yang telah diselesaikan, dan berkolaborasi dengan tim scrum untuk mendiskusikan setiap perubahan yang diinginkan oleh pelanggan.
\end{abstract}

Kata Kunci: Manajemen proyek tangkas, project owner, kerangka kerja scrum. 


\section{PENDAHULUAN}

Perkembangan dalam dunia TI berkembang sangat pesat dan cenderung memiliki lingkungan bisnis yang sering berubah dan lebih dinamis (Raj \& Sinha, 2020). Saat ini perusahaan penyedia jasa layanan TI dituntut dalam melaksanakan multi proyek dalam waktu yang bersamaan dengan ketidakpastian proyek yang sangat tinggi (Stare, 2014). Perusahaan penyedia jasa layanan TI berjuang dengan memberikan sebuah produk perangkat lunak yang berfungsi tetap fleksibel dan mudah beradaptasi terhadap perubahan yang terjadi. Perusahaan dalam menjalankan sebuah proyek biasanya menyediakan project manager untuk memimpin dan mengekoordinasikan setiap kegiatan yang akan dikerjakan pada proyek tersebut. Project manager dituntut dalam meningkatkan penyelesaian proyek melalui metodologi demi mewujudkan efektivitas dan efisiensi kegiatan proyek seperti inovasi, teknologi, berbagai ketidakpastian kebutuhan proyek, dan kerugian akibat keterlambatan proyek yang dapat diselesaikan sesuai dengan perencanaan, resource dan waktu yang terbatas (Ismail \& Mansor, 2018).

Sejak penerbitan agile manifesto pada tahun 2001, metode agile telah mengambil peran penting dalam pengelolaan proyek TI untuk meningkatkan produktivitas dalam menghadapi proyek yang dinamis (Lechler \& Yang, 2017). Metode agile merupakan filosofi dan praktik untuk mengatur pengembangan dalam TI (Kanaparan \& Strode, 2021). Dalam wawancara dengan Bowles Jackson penulis manifesto tersebut menyatakan bahwa metode agile tidak hanya cocok pada proyek TI namun juga berguna untuk semua jenis proyek yang menghadapi ketidakpastian dan kedinamisan (Stare, 2013). Metodologi agile menyediakan sarana untuk menanggapi konteks efektivitas dan efisiensi dalam pelaksanaan proyek serta menanggapi kebutuhan customers yang tidak pasti serta dinamis. Agile Project Management (APM) telah membuktikan keberhasilan pada banyak perusahaan TI dan mencapai kesuksesan untuk kestabilan perusahaan (Madampe, 2017).

Metodologi agile memiliki kerangka kerja yang populer salah satunya yakni scrum. Kerangka kerja scrum dalam pengimplementasiannya terhadap proyek dapat meningkatkan kerja sama antar bagian project owner dan scrum team, pengurangan biaya dan meningkatkan kecepatan waktu pengembangan aplikasi (Raj \& Sinha, 2020). Scrum dibentuk pada 3 peran penting oleh project owner, scrum master, dan development team. Project owner sering disebut project manager pada traditional project management.

PT.XYZ merupakan perusahaan penyedia jasa konsultasi TI dan sistem integrasi perangkat lunak yang mendukung bisnis enterprise, layanan data center dan cloud, dan manage service. Sebagai perusahaan penyedia konsultasi dan sistem integrasi, PT.XYZ sedang menjalani banyak proyek dibidang TI baik dari pembangunan aplikasi. PT.XYZ mempercayakan beberapa project owner untuk memimpin, mengelola, menjalankan dan mengoptimalkan proyek yang sedang dijalankan. Saat pelaksanaannya proyek yang sedang dijalani terdapat banyak perubahan dari segi design awal aplikasi dengan alasan untuk meningkatkan kualitas produk yang ingin dihasilkan oleh customers. Karena alasan ketidakpastian dan kedinamisan proyek yang sedang dijalankan, beberapa project owner menjalankan metodologi agile project management demi mewujudkan keefektivitasan dan keefisiensian kegiatan proyek agar berhasil dalam menjalankan proyek tepat sesuai waktu yang telah ditentukan. Project owner memiliki peran kritis karena sebagai penghubung antara keinginan customers dan scrum team yang mengerjakan proyek.

Atas dasar latar belakang diatas, maka ruang lingkup penelitian ini yakni terkait penggunaan agile project management dengan metode scrum pada PT.XYZ yang sedang menjalankan beberapa proyek dengan kedinamisan proyek yang cukup tinggi. Fokus penelitian secara khusus diletakkan pada peran dari project owner agar tercipta keberhasilan dalam menjalankan proyek. Tujuan utamanya adalah untuk menyelidiki peran dan tanggung jawab project owner saat menjalankan proyek di PT.XYZ dengan menggunakan metodologi agile

Jurnal Manajemen dan Organisasi

(JMO),

Vol. 12 No. 3,

Hal. 166-176 


\section{Tinjauan Pustaka}

\section{Agile Project Management}

Sebelum kemunculan agile project management telah terjadi banyak metode berbasis trial and error dalam pengembangan perangkat lunak (Lei et al., 2017). Baru-baru ini banyak tinjauan pustaka sistematis tentang definisi agile project management salah satunya yakni mendefinisikan bahwa agile project management berkaitan dengan kompleksitas dan ketidakpastian dalam proyek dan terciptanya perubahan yang tidak direncanakan (Ruhe \& Wohlin, 2014). Secara umum diketahui bahwa metodologi agile pada awalnya dikembangkan dalam upaya untuk memperbaiki metode tradisional yang ada dalam implementasi proyek (Coyle \& Conboy, 2012). Metode agile memiliki pandangan yang berbeda dengan proyek yang menggunakan metode tradisional seperti waterfall dan prototype (Srivastava et al., 2017). Metode agile project management menguraikan tugas menjadi beberapa tingkatan prioritas dengan perencanaan setiap pengerjaan tugas yang ingin dicapai dibatasi waktu hingga 1-4 minggu.

Pada Gambar 1 menjelaskan agile life cycle, pada awalnya customers akan menjelaskan gambaran besar terkait fitur-fitur yang akan dikembangkan, lalu fitur tersebut akan dibuat menjadi task yang diprioritaskan untuk pekerjaan yang kritis yang disimpan pada feature product backlog lalu akan dikerjakan setiap tahapan planning, developing, testing dan implementing/release. Prinsipnya proses pengerjaan proyek yang dilakukan oleh scrum team, project owner, dan customers harus memadukan roles, relationships, dan activities. Tahapan tersebut akan terus dikembangkan dalam siklus berulang dimana setiap tahapan akan selalu terhubung dengan tahapan selanjutnya (Madampe, 2017).

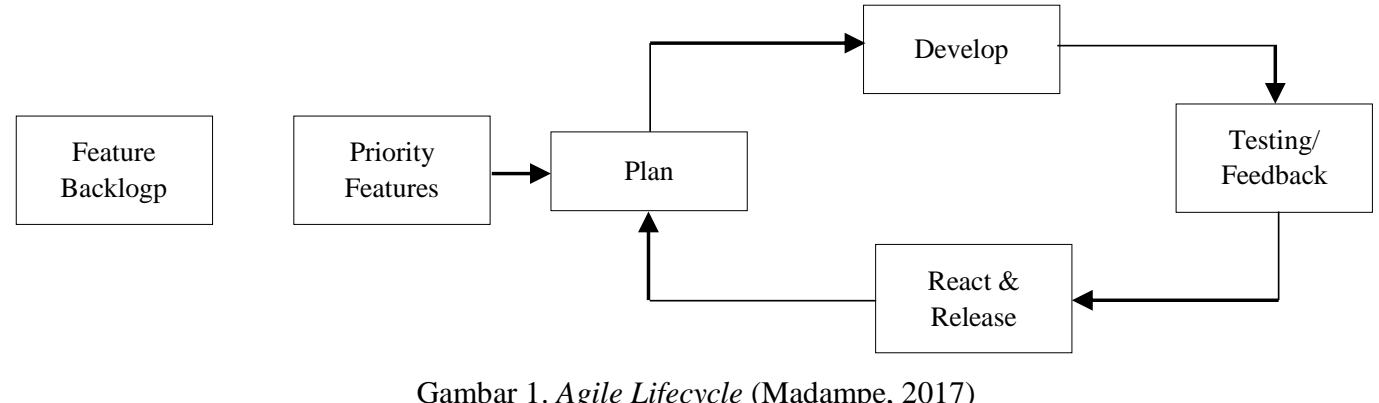

Gambar 1. Agile Lifecycle (Madampe, 2017)

Agile project management merupakan perpaduan antara konsep traditional project management (TPM) dengan fleksibilitas, lightweight, kolaboratif, dan kemudahan beradaptasi terhadap perubahan yang sering terjadi (Salameh, 2014). Pada Gambar 2 menjelaskan proses metode agile project management didasarkan pada perencanaan kebutuhan yang efisien, dan desain solusi untuk memulai proyek menggunakan iterasi penyampaian yang singkat dan pembelajaran yang berkelanjutan seperti pada gambar 1, lalu iterasi selanjutnya memerlukan perencanaan yang lebih rinci, analisa requirement, desain, pelaksanaan, testing, dan delivery product kepada customers (Salameh, 2014). Pada setiap akhir dari iterasi harus hasil dari product backlog yang dikerjakan oleh scrum team harus di delivery kepada customers untuk mendapatkan feedback juga mengurangi risiko kegagalan karena terlalu banyak perubahan (Madampe, 2017). 


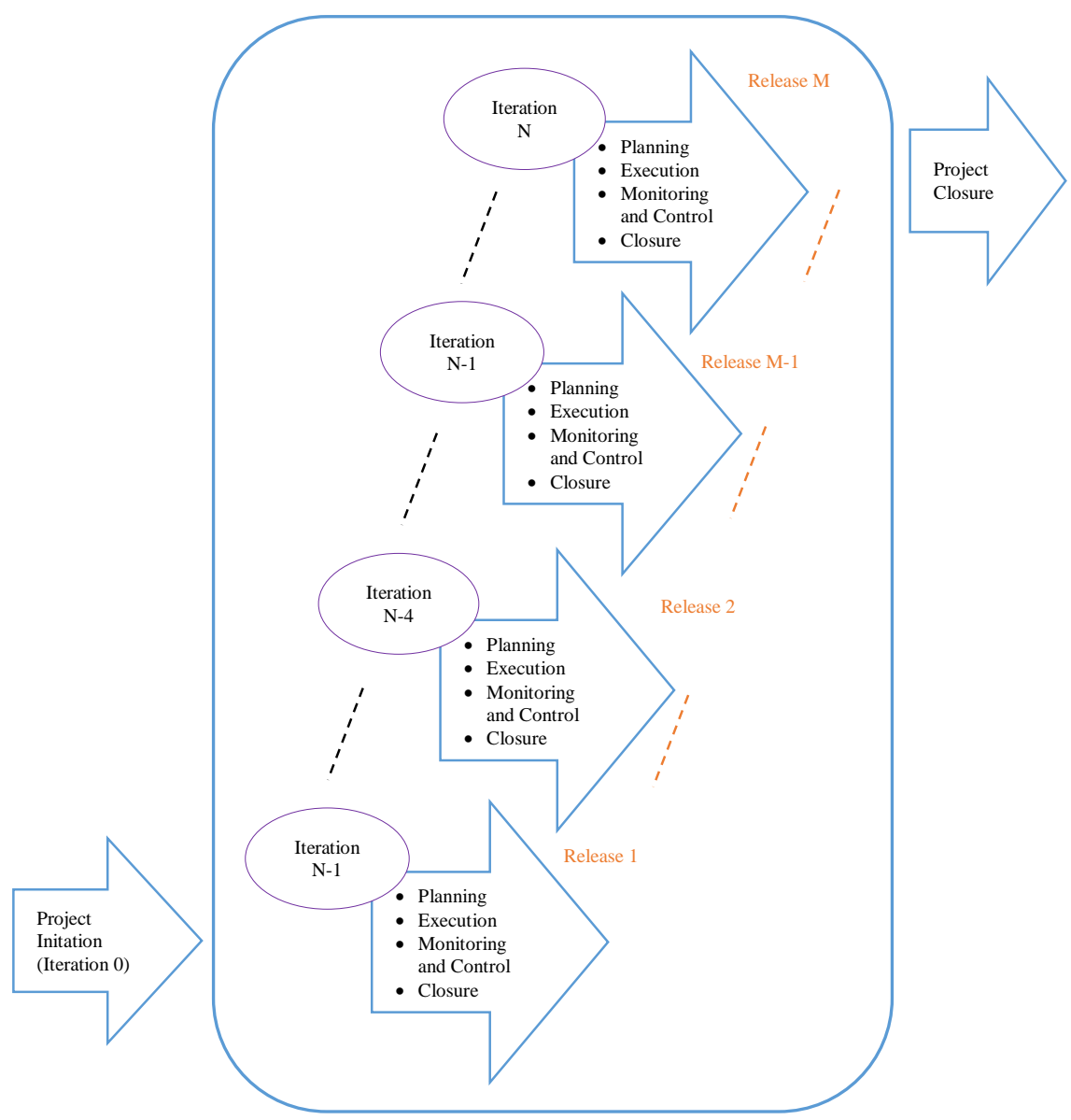

Gambar 2. Agile Success Factor (Aldahmash et al., 2017)

Faktor keberhasilan agile project management tidak dapat terlepas pada pendekatan klasik ISO 21500 tentang project management yang diklasifikasikan seperti pada Gambar 3 (Aldahmash et al., 2017).

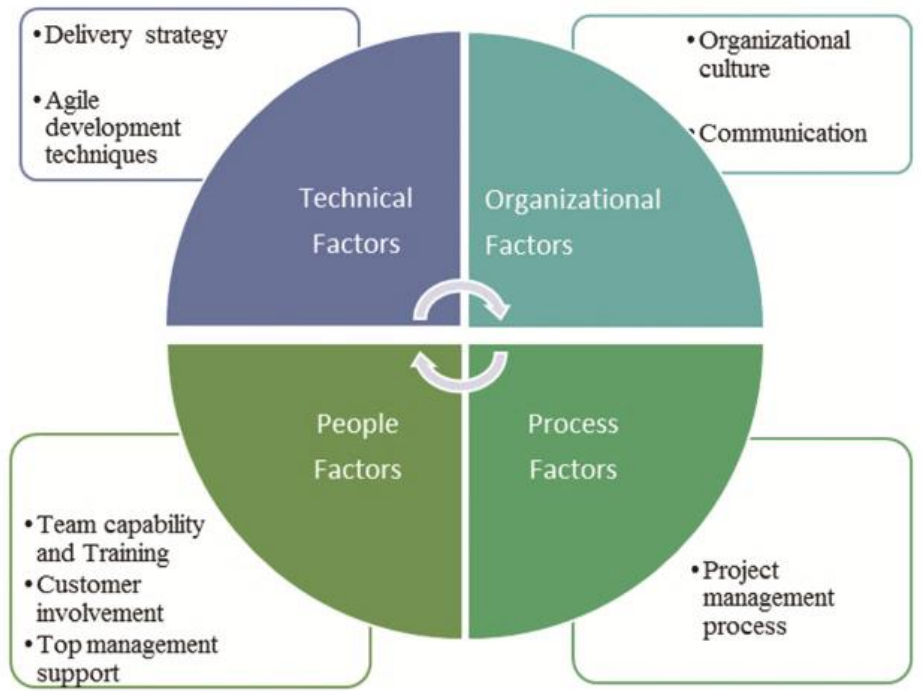

Jurnal Manajemen dan Organisasi

Vol. 12 No. 3,

Hal. 166-176 
a) Technical Factors

Strategi delivery harus jelas dalam proyek yang sedang dijalankan dengan setiap anggota mengetahui perannya dalam strategi yang dijalankan. Selain itu dalam teknik agile development setiap tim harus telah terbiasa dengan metode yang dipilih.

b) People Factors

Keterlibatan dan dukungan top management sangat penting untuk keberhasilan proyek agile. Selain itu pada proyek agile kompetensi setiap anggota sangat penting. Untuk memaksimalkan keberhasilan proyek harus dibangun dengan tim yang telah bertalenta. Kompetensi yang dimiliki oleh tim harus ditunjang dengan pelatihan yang cukup.

c) Process Factors

Pada tahapan awal proyek, penting bagi seorang project management untuk membuat rencana proyek yang tepat. Pemilihan proses project management yang tepat berkontribusi pada keberhasilan proyek agile development project yang berkualitas. Proses project management yang dipilih harus memperdayakan anggota tim dan melihat bakat anggota tim yang dimiliki. Agile project menghasilkan banyak iterasi yang memerlukan pendekatan project management yang fleksibel.

d) Organizational Factors

Budaya organisasi yakni sekumpulan faktor yang dapat mempengaruhi proyek agile. Organisasi harus memiliki budaya dinamis untuk menanggapi perubahan yang sering terjadi selama agile development lifecycle. Faktor komunikasi sangat penting untuk keberhasilan proyek agile. Sifat dari proyek agile yang mencakup keterlibatan customers, feedback dari costumers yang terlalu sering, perubahan yang sangat dinamis akan membutuhkan komunikasi yang efisien antara tim proyek dengan customers.

Saat ini banyak metode agile dengan konsep yang sama namun yang paling banyak digunakan adalah Scrum, dan Extreme Programming (XP), selain itu Lean, Crystal, Feature Driven Development (FDD), Dynamic Systems Development Method (DSDM) juga digunakan (Madampe, 2017).

\section{Scrum Framework}

Scrum merupakan salah satu kerangka kerja pada agile project management yang dikembangkan oleh Ken Schwaber dan Jeff Sutherland (Cervone, 2011). Scrum digunakan dalam pekerjaan yang kompleks dan dinamis, dan menyediakan sebuah kerangka kerja yang digunakan scrum team dalam melihat pandangan yang akurat tentang fakta selama proyek sedang berjalan demi mancapai tujuan dari proyek tersebut (Azanha et al., 2017). Filosofi yang mendasari scrum yakni bahwa customer sering berubah pikiran tentang produk yang akan diimplementasi, maka scope proyek yang akan dijalankan tidak dapat sepenuhnya dijabarkan dari awal (Campbell et al., 2016). Scrum menjadi salah satu metodologi agile yang memberikan fleksibilitas untuk mengontrol dan mengelola persyaratan serta pengembangan perangkat lunak (Hayat et al., 2019). Ide dibalik scrum yakni untuk menangani kelemahan yang ada pada pengembangan metodologi tradisional (Anwer et al., 2017).

Pada kerangka kerja scrum terdiri dari tiga peran utama dan memiliki tugas yang berbeda dalam prakteknya yakni : project owner, scrum master, dan scrum development team (Streule et al., 2016). Project owner bertanggung jawab untuk memaksimalkan kualitas proyek yang dijalankan, memonitoring pekerjaan development team, dan bertanggung jawab untuk mengelola product backlog. Scrum master memiliki peran untuk memastikan bahwa proyek dilaksanakan sesuai dengan praktik, nilai, dan aturan scrum serta sesuai durasi rencana yang telah ditetapkan. Development team biasanya terdiri dari 3-9 orang professional yang melakukan tugas untuk memberikan kualitas terbaik untuk setiap sprint yang diambil dan meningkatkan kualitas proyek dari setiap sprint yang telah diambil. Dalam banyak kasus, scrum memerlukan modifikasi peran atau proses yang baru untuk memeperkenalkan diperkenalkan metode yang ada, karena jika tidak akan berisiko menghilangkan manfaat yang dijanjikan oleh penerapan agile project management 
(Hron \& Obwegeser, 2018). Artefak scrum meliputi product backlog, sprint backlog, dan sprint execution (Hassani-Alaoui et al., 2020).

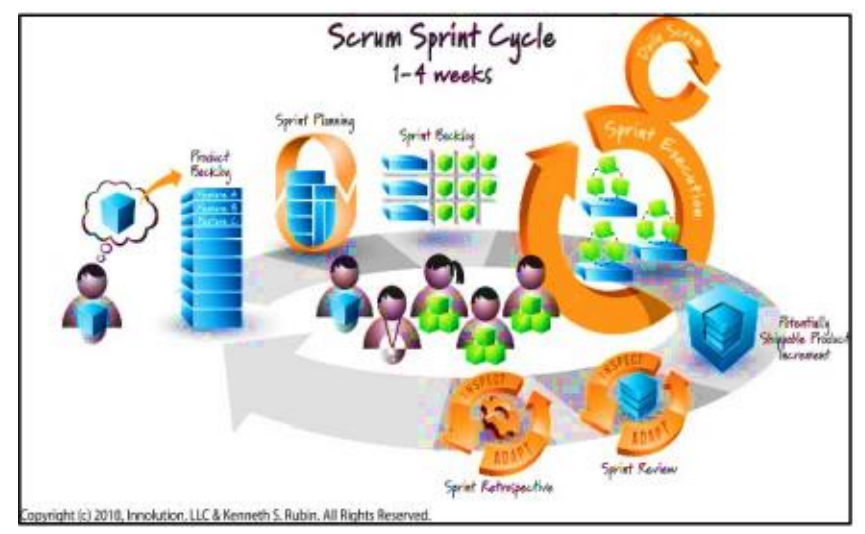

Gambar 4. Kerangka Pemikiran (May et al., 2016)

Scrum dijalankan pada periode yang tetap seperti pada Gambar 4 yakni awalnya dilakukan suatu meeting terkait perencanaan proyek, hal ini berfungsi sebagai wadah bagi semua orang yang bersangkutan dalam proyek untuk bersama-sama menetapkan pedoman proyek dan tujuan yang ingin dicapai. Pedoman proyek dapat berubah seiring berjalannya waktu dan dapat dibicarakan bersama saat sprint planning meeting mendatang. Sprint merupakan lifecycle dengan durasi tetap yakni 1-4 minggu, dalam hal ini project owner yang bertugas untuk menentukan periode setiap sprint yang berjalan. Aktifitas yang ada pada 1 sprint meliputi sprint, sprint planning, daily scrum, sprint review dan sprint retrospective (Bhavsar et al., 2020). Sprint planning meeting bertujuan untuk mereview feedback yang diberikan oleh customers dan menetapkan tugas yang harus dikerjakan untuk sprint berikutnya. Saat sprint planning meeting dibagi menjadi dua yakni yang pertama product owner harus menetapkan urutan prioritas product backlog pada setiap sprint yang dijalankan dan yang kedua scrum team bersama dengan project owner akan menentukan periode lama pengerjaan dari setiap sprint yang dijalankan. Dari kedua meeting tersebut product owner dapat mengurutkan product backlog yang harus dijadikan prioritas pengerjaan agar sprint dapat selalu memperhatikan waktu yang telah ditetapkan untuk penyelesaiannya. Feedback dari setiap sprint yang telah dijalankan direview saat awal ingin mengerjakan sprint selanjutnya.

\section{Peran dan Tanggung Jawab Project Owner dalam Scrum Framework}

Scrum dibentuk pada tiga peran penting oleh project owner, scrum master, dan development team. Dari anggota tim scrum tersebut memiliki peran yang berbeda-beda dalam pengelolaan dan pengawasan suatu proyek yang sedang dijalankan. Dari ketiga peran tersebut, peran project owner memiliki salah satu peran terpenting dalam scrum dan seringkali yang paling rumit diantara yang lainnya. Project owner adalah satu-satunya orang yang pada akhirnya bertanggung jawab atas keberhasilan dan kegagalan proyek (Matthias et al., 2019). Project owner harus memiliki karakteristik keterampilan komunikasi dan pandai bernegosiasi, memiliki kewenangan dan dukungan yang cukup dari manajemen eksekutif untuk memimpin proyek yang dijalankan dan mengkoordinasikan keinginan para stakeholders (Sverrisdottir et al., 2014).

Peran Project owner merupakan kombinasi antara otoritas dan tanggung jawab, dengan juga memasukkan elemen peran project manager, marketing, dan business analyst (Rubin, 2012). Project Owner bertanggung jawab untuk memaksimalkan nilai produk dengan memberikan laba atas investasi (ROI) ke perusahaan (Milanov \& Njeguš, 2012). Secara umum, siapa pun yang telah berperan menjadi project owner harus dapat bekerja dengan customers untuk mengumpulkan kebutuhan dan kemudian bekerja dengan scrum team untuk menciptakan produk atau solusi yang memenuhi kebutuhan tersebut (Moreira, 2013). Project Owner menghargai 
peningkatan efisiensi, namun juga mengindentifikasi faktor-faktor negatif seperti keinginan hasil software development yang tetap tidak mengalami perubahan (Shastri et al., 2021).

Project Owner bertanggung jawab untuk pembiayaan proyek selama lifecycle proyek tersebut serta mengedepankan persyaratan dan tujuan proyek, memelihara dan memprioritaskan product backlog untuk proyek yang sedang dibangun dan dikembangkan, product backlog harus berada dibawah perhatian dan pengawasan yang konstan karena berpengaruh terhadap sprint planning yang telah ditentukan, kolaborasi yang baik dengan scrum team dan customers agar tercipta keberhasilan proyek sesuai dengan visi dan tujuan yang telah ditetapkan dalam proyek yang sedang dijalankan (Sverrisdottir et al., 2014).

\section{METODE PENELITIAN}

Metode penelitian yang digunakan menggunakan metode kualitatif bersifat deskriptif. Metode pendekatan kualitatif bersifat deskriptif adalah metode pengolahan data dengan cara mengumpulkan data berdasarkan faktor yang mendukung penelitian lalu menganalisa faktor tersebut untuk dapat mencari perannya (Prabowo \& Heriyanto, 2013). Penelitian dengan pendekatan kualitatif menggunakan data primer dan sekunder (Dana \& Durnez, 2015). Data primer bersumber dari wawancara dengan lima project owner yang bekerja di PT.XYZ dan pernah atau sedang mengerjakan proyek menggunakan metodologi agile project management dan data sekunder bersumber dari literatur yang digunakan saat penelitian berlangsung. Project owner yang akan menjalani wawancara telah memiliki kualifikasi pengalaman minimal 5 tahun menjadi project manager dan minimal telah menjalankan tiga proyek dengan metode agile project management. Metode investigasi yang diadopsi merupakan studi kasus tunggal yakni perusahaan PT.XYZ yang bergerak dibidang TI dengan memiliki beberapa proyek dengan kedinamisan perubahan implementasi yang cukup tinggi. Teknik pengumpulan data melalui wawancara dengan beberapa pertanyaan yang bertujuan untuk mengetahui bagaimana project owner mendefinisikan peran dan tanggung jawab dalam pengelolaan proyek jika scrum diterapkan. Pengumpulan informasi dari wawancara dilakukan dengan analisa setiap jawaban untuk mengetahui peran project owner untuk keberhasilan proyek yang sedang dijalankan dengan menggunakan metode scrum. Hasil wawancara selanjutnya akan diolah dan disusun agar dapat dilakukan pembahasan sesuai dengan tujuan yang ingin dicapai.

\section{HASIL DAN PEMBAHASAN}

Dalam pengimplementasian kerangka kerja scrum pada agile project management, scrum dibentuk pada 3 peran penting oleh project owner, customers, dan scrum team. Dari ketiga peran tersebut project owner memiliki peran yang cukup kritis karena sebagai penghubung antara customers dengan scrum team seperti yang terlihat pada Gambar 5. Project owner harus memahami kebutuhan yang diinginkan oleh customers dengan peka terhadap kebutuhan customers yang menonjolkan kualitas dan perubahan yang tidak pasti dan tetap memperhatian kualitas yang tinggi, selain itu memahami scrum team dalam mengirimkan layanan produk yang diinginkan oleh customers agar memberikan kualitas yang maksimal dan terima oleh customers.

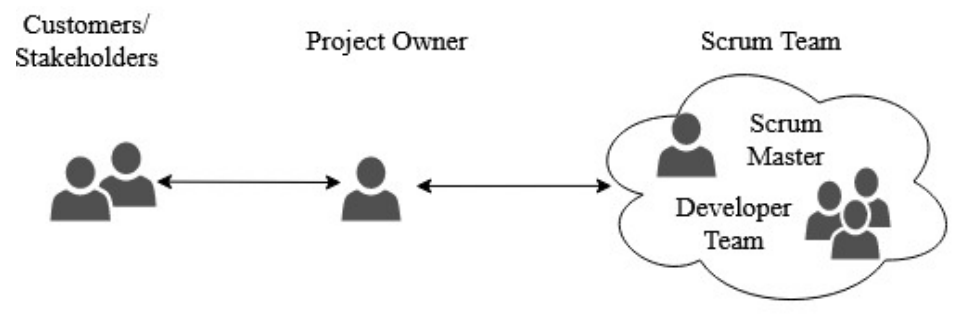

Gambar 5. Flow Peran Project Owner

Dari hasil wawancara bersama lima project owner terkait peran dan tanggung jawab dalam implementasi scrum dapat disajikan dalam bentuk tabel seperti pada Tabel 1. 
Tabel 1. Peran dan tanggung jawab project owner

\begin{tabular}{|c|c|c|c|c|c|}
\hline Peran dan Tanggung Jawab & Responden 1 & Responden 2 & Responden 3 & Responden 4 & Responden 5 \\
\hline $\begin{array}{l}\text { Mendefinisikan visi, misi yang } \\
\text { ingin dicapai serta scope of } \\
\text { work dalam proyek yang } \\
\text { dijalankan }\end{array}$ & $\sqrt{ }$ & $\sqrt{ }$ & $\sqrt{ }$ & $\sqrt{ }$ & $\sqrt{ }$ \\
\hline $\begin{array}{l}\text { Penyusunan alokasi budget } \\
\text { proyek }\end{array}$ & $\sqrt{ }$ & $\sqrt{ }$ & $\sqrt{ }$ & $\sqrt{ }$ & $\sqrt{ }$ \\
\hline $\begin{array}{l}\text { Pemilihan development team } \\
\text { yang akan mengerjakan produk }\end{array}$ & $\sqrt{ }$ & $\sqrt{ }$ & - & $\sqrt{ }$ & - \\
\hline $\begin{array}{l}\text { Penentuan prioritas product } \\
\text { backlog }\end{array}$ & $\sqrt{ }$ & $\sqrt{ }$ & $\sqrt{ }$ & $\sqrt{ }$ & $\sqrt{ }$ \\
\hline $\begin{array}{l}\text { Penyusunan setiap sprint dalam } \\
\text { product backlog }\end{array}$ & $\sqrt{ }$ & $\sqrt{ }$ & $\sqrt{ }$ & $\sqrt{ }$ & $\sqrt{ }$ \\
\hline $\begin{array}{l}\text { Memonitoring tahapan sprint } \\
\text { yang dikerjakan oleh scrum } \\
\text { team }\end{array}$ & $\sqrt{ }$ & $\sqrt{ }$ & $\sqrt{ }$ & $\sqrt{ }$ & $\sqrt{ }$ \\
\hline $\begin{array}{l}\text { Mengadakan daily meeting } \\
\text { selama } 15 \text { menit bersama } \\
\text { scrum team }\end{array}$ & $\sqrt{ }$ & $\sqrt{ }$ & - & $\sqrt{ }$ & $\sqrt{ }$ \\
\hline $\begin{array}{l}\text { Mengadakan meeting bersama } \\
\text { customers dan scrum team } \\
\text { untuk setiap sprint yang telah } \\
\text { selesai dikerjakan }\end{array}$ & $\sqrt{ }$ & $\sqrt{ }$ & $\sqrt{ }$ & $\sqrt{ }$ & $\sqrt{ }$ \\
\hline $\begin{array}{l}\text { Kolaborasi dengan scrum team } \\
\text { untuk pembahasan setiap } \\
\text { perubahan yang diinginkan } \\
\text { oleh customer }\end{array}$ & $\sqrt{ }$ & $\sqrt{ }$ & $\sqrt{ }$ & $\sqrt{ }$ & $\sqrt{ }$ \\
\hline
\end{tabular}

Seperti yang disajikan pada Tabel 1 , semua responden sepakat bahwa saat awal ingin mengerjakan sebuah proyek, project owner harus dapat mendefinisikan dan menjelaskan kepada semua orang yang akan terlibat dalam proyek tersebut visi, misi, tujuan, dan scope of work (SoW) yang ingin dicapai dengan rentang waktu yang telah disepakati oleh customers.

Setelah mengetahui dengan jelas visi, misi, tujuan, dan scope of work (SoW) dari proyek yang akan dijalankan, saat wawancara para project owner ditanya lebih lanjut lagi terkait bagaimana pengelolaan budget dengan alokasi yang telah ditetapkan dan disepakati bersama dengan customers. Semua responden setuju bahwa penentuan setiap anggaran alokasi budget yang dibutuhkan untuk jalannya proyek menjadi tanggung jawab project owner untuk menyusunnya. Responden dua dalam hal alokasi biaya proyek berpendapat "pengalokasian biaya sangat penting dipersiapkan agar perusahaan masih tetap mendapatkan margin keuntungan apalagi dengan kondisi proyek yang sangat dinamis dan tidak mudah ditebak".

Dilanjutkan dengan pertanyaan dalam wawancara mengacu pada jumlah pengalokasian developer team yang akan mengerjakan proyek agar masih memenuhi budget yang tersedia dan mampu mengerjakan produk yang diinginkan oleh customer dengan tepat waktu. Dalam menjawab pertanyaan ini dua responden yakni responden tiga dan lima tidak sepakat bahwa untuk pengalokasian developer team menjadi tanggung jawab project owner. Responden tiga hanya menjelaskan bahwa pemilihan development team bukan tugas project owner akan tetapi menjadi tanggung jawab dari scrum master, Responden lima menjelaskan dengan tegas "project owner hanya menyebutkan jumlah development team yang dibutuhkan dalam proyek namun untuk pemilihan development team menjadi tanggung jawab scrum master untuk mengassignnya karena yang lebih mengetahui skill dan kualitias setiap orang development yakni scrum master". Akan tetapi responden satu, dua, dan empat masih berpendapat bahwa project owner harus masih ikut andil dalam pemilihan development team bersama dengan scrum master karena untuk mendiskusikan penentuan waktu yang dibutuhkan oleh development team untuk setiap sprint yang dijalankan.

Lebih lanjut para project owner ditanya terkait bagaimana mereka mengelola proses penentuan prioritas product backlog, penyusunan setiap sprint yang akan dijalankan dan monitoring untuk setiap tahapan sprint yang sedang dijalankan oleh scrum team. Dari kelima 
responden yang diwawancara mereka semua sepakat bahwa penentuan product backlog, dan penentuan setiap sprint dalam product backlog menjadi tugas dan tanggung jawab dari project owner. Responden empat menjelaskan bahwa "critical success factor saat implementasi metode scrum dalam proyek yang dijalankan yakni saat penentuan product backlog dan penentuan prioritas sprint dalam product backlog yang akan dikerjakan oleh scrum master. Project owner juga bertanggung jawab dalam memonitoring setiap tahapan sprint yang dijalankan agar masih sesuai timeline proyek."

Ulasan lain yakni pertanyaan terkait dengan pengadaan daily meeting bersama internal scrum team, pengadaan meeting dengan customers untuk setiap sprint yang telah diselasaikan oleh scrum team, dan setelah itu pembahasan dengan scrum team untuk setiap perubahan yang diinginkan oleh customers. Hampir semua responden sepakat bahwa daily meeting diperlukan untuk membantu monitoring tahapan setiap sprint yang sedang dikerjakan namun responden tiga berbeda pendapat yakni "daily meeting setiap pagi selama maksimal 15 menit bersama internal scrum team tidak terlalu efektif untuk skala proyek yang cukup besar, daily meeting dapat diganti dengan weekly meeting agar tidak mengganggu scrum team menyelesaikan sprint yang sedang dikerjakan. Weekly meeting dilaksanakan untuk mengupdate progress tahapan sprint yang sedang dikerjakan oleh scrum team”. Mengatur dan mengadakan meeting dengan customers untuk setiap sprint yang selesai dikerjakan, semua responden sepakat bahwa itu telah menjadi tanggung jawab dari project owner. Dari hasil presentasi progress produk yang sedang dikerjakan, jika customers menghendaki adanya beberapa perubahan dalam produk yang sedang di kembangkan project owner memiliki tugas untuk mengkompulir setiap perubahan yang diinginkan oleh customers. Responden satu berpendapat "selesai melakukan meeting dengan customers untuk setiap sprint yang selesai dikerjakan, jika customers menginginkan sedikit perubahan maka project owner dan scrum team harus mengadakan meeting internal lanjutan untuk membahas perubahan yang diinginkan oleh customers dengan memperhatikan perubahan tersebut tidak mempengaruhi sprint yang akan dikerjakan selanjutnya dan timeline proyek masih on schedule."

Namun, dari semua hal tersebut tanggung jawab lain yang harus dilaksanakan oleh project owner yakni mengkomunikasikan setiap tahapan proyek, faktor-faktor yang menghambat jalannya proyek, dan keinginan customers diluar SoW yang telah disepakati kepada internal stakeholders agar masih termonitor oleh perusahaan.

\section{KESIMPULAN}

Dalam menjalankan sebuah proyek suatu perusahaan akan menyediakan project manager untuk mengelola proyek yang sedang dijalankan. Metodologi agile project management menyediakan sarana untuk menanggapi konteks efektif dan efisiensi dalam pelaksanaan proyek serta menanggapi kebutuhan customers yang tidak pasti dan dinamis. Untuk menanggapi hal tersebut beberapa project manager menggunakan scrum framework pada salah satu metode agile. Scrum dibentuk pada 3 peran penting oleh project owner, scrum master, dan scrum team.

Dengan menggunakan metode penelitian kualitatif bersifat deskriptif, penelitian ini dilaksanakan untuk mengetahui peran dan tanggung jawab project owner saat menjalankan beberapa proyek di PT.XYZ dengan menggunakan metodologi agile project management framework scrum. Metode penelitian kualitatif bersumber dari data primer dan data sekunder. Data primer bersumber dari wawancara dengan 5 project owner yang bekerja di PT.XYZ dan pernah atau sedang mengerjakan proyek menggunakan metodologi agile project management dan data sekunder bersumber dari literatur yang digunakan saat penelitian berlangsung.

Hasil yang diperoleh dari wawancara yakni peran project owner sangat kritis karena sebagai penghubung antara customers dengan scrum team. Project owner harus memahami kebutuhan yang diinginkan oleh customers dengan peka terhadap kebutuhan customers yang menonjolkan kualitas dan perubahan yang tidak pasti, selain itu memahami scrum team dalam mengirimkan layanan produk yang diinginkan oleh customers agar memberikan kualitas yang maksimal dan terima oleh customers. Tanggung jawab project owner yakni seperti menjelaskan 
SoW dan tujuan yang ingin dicapai dalam proyek tersebut, penyusunan anggaran biaya dalam proyek, pengalokasian development team yang akan mengerjakan produk, menentukan prioritas product backlog dan sprint yang akan dijalankan, memonitoring setiap tahapan sprint yang sedang dikerjakan oleh developer team, mengadakan daily meeting selama maksimal 15 menit dengan scrum team, mengatur dan mengadakan meeting dengan customers dan scrum team untuk setiap sprint yang telah selesai dikerjakan, dan kolaborasi dengan scrum team untuk pembahasan setiap perubahan yang diinginkan oleh customers.

\section{DAFTAR PUSTAKA}

Aldahmash, A., Gravell, A. M., \& Howard, Y. (2017). A Review on the Critical Success Factors of Agile Software Development. Communications in Computer and Information Science, 748, 1-9. https://doi.org/10.1007/978-3-319-64218-5_41.

Anwer, F., Aftab, S., Shah Muhammad Shah, S., Waheed, U., Shah, S. M., \& Waheed, U. (2017). Comparative analysis of two popular agile process models: extreme programming and scrum. International Journal of Computer Science and Telecommunications, 8(2), 1-7.

Azanha, A., Argoud, A. R. T. T., Junior, J. B. de C., \& Antoniolli, P. D. (2017). Agile project management with Scrum: A case study of a Brazilian pharmaceutical company IT project. International Journal of Managing Projects in Business, 10(1), 121-142. https://doi.org/10.1108/IJMPB-06-2016-0054.

Bhavsar, K., Shah, V., \& Gopalan, S. (2020). Scrum: An Agile Process Reengineering in Software Engineering. International Journal of Innovative Technology and Exploring Engineering, 9(3), 840-848. https://doi.org/10.35940/ijitee.c8545.019320.

Campbell, J., Kurkovsky, S., Tafliovich, A., \& Liew, C. W. (2016). Scrum and agile methods in software engineering courses. SIGCSE 2016 - Proceedings of the 47th ACM Technical Symposium on Computing Science Education, 319-320. https://doi.org/10.1145/2839509.2844664.

Cervone, H. F. (2011). Understanding agile project management methods using Scrum. OCLC Systems and Services, 27(1), 18-22. https://doi.org/10.1108/10650751111106528

Coyle, S., \& Conboy, K. (2012). A case study of risk management in agile systems development. 17th European Conference on Information Systems, ECIS 2009.

Hassani-Alaoui, S., Cameron, A.-F., \& Giannelia, T. (2020). "We Use Scrum, but ...": Agile Modifications and Project Success. Proceedings of the 53rd Hawaii International Conference on System Sciences, 6257-6266. https://doi.org/10.24251/hicss.2020.765

Hayat, F., Rehman, A. U., Arif, K. S., Wahab, K., \& Abbas, M. (2019). The Influence of Agile Methodology (Scrum) on Software Project Management. Proceedings - 20th IEEE/ACIS International Conference on Software Engineering, Artificial Intelligence, Networking and Parallel/Distributed Computing, $\quad$ SNPD 2019, 145-149. https://doi.org/10.1109/SNPD.2019.8935813.

Hron, M., \& Obwegeser, N. (2018). Scrum in practice : an overview of Scrum adaptations. Proceedings of the 51st Hawaii International Conference on System Sciences, 5445-5454. https://doi.org/10.24251/hicss.2018.679.

Ismail, M. F. bin, \& Mansor, Z. (2018). Agile Project Management: Review, Challenges and Open Issues. Advanced Science Letters, 24(7), 5216-5219. https://doi.org/10.1166/asl.2018.11705.

Kanaparan, G., \& Strode, D. E. (2021). A Theory of Coordination: From Propositions to Hypotheses in Agile Software Development. Proceedings of the 54th Hawaii International Conference on System Sciences, 6795-6805.

Lechler, T. G., \& Yang, S. (2017). Exploring the Role of Project Management in the Development of the Academic Agile Software Discourse: A Bibliometric Analysis. Project Management 
Lei, H., Ganjeizadeh, F., Jayachandran, P. K., \& Ozcan, P. (2017). A statistical analysis of the effects of Scrum and Kanban on software development projects. Robotics and ComputerIntegrated Manufacturing, 43, 59-67. https://doi.org/10.1016/j.rcim.2015.12.001.

Madampe, M. A. K. G. (2017). Successful Adoption of Agile Project Management in Software Development Industry. International Journal of Computer Science and Information Technology Research, 5(4), 27-33.

Matthias, M., Schindler, C., \& Slany, W. (2019). Introducing Agile Product Owners in a FLOSS Project. IFIP Advances in Information and Communication Technology, 556, 38-43.

May, J., York, J., \& Lending, D. (2016). Teaching Tip Play ball: Bringing Scrum into the Classroom. Journal of Information Systems Education, 27(2), 87-92.

Milanov, G., \& Njeguš, A. (2012). Analysis of Return on Investment in Different Types of Agile Software Development Project Teams. Informatica Economica Journal, 16(4), 7-18.

Moreira, M. (2013). Being Agile - Your Roadmap to Successful Adoption of Agile. Apress.

Prabowo, A., \& Heriyanto. (2013). Analisis Pemanfaatan Buku Elektronik (E-Book) Oleh Pemustaka di Perpustakaan SMA Negeri 1 Semarang. Jurnal Ilmu Perpustakaan, 2(2), 19.

Raj, P., \& Sinha, P. (2020). Project management in era of agile and devops methodlogies. International Journal of Scientific and Technology Research, 9(1), 1024-1033.

Rubin, K. S. (2012). Essential Scrum - a Practical Guide to the Most Popular Agile Process.

Ruhe, G., \& Wohlin, C. (2014). Software Project Management in a Changing World. In Software Project Management in a Changing World (Vol. 9783642550). https://doi.org/10.1007/9783-642-55035-5_7.

Salameh, H. (2014). What, When, Why, and How? A Comparison between Agile Project Management and Traditional Project Management Methods. International Journal of Business and Management Review, 2(5), 52-74.

Shastri, Y., Hoda, R., \& Amor, R. (2021). The role of the project manager in agile software development projects. Journal of Systems and Software, 173. https://doi.org/10.1016/j.jss.2020.110871.

Srivastava, A., Bhardwaj, S., \& Saraswat, S. (2017). SCRUM model for agile methodology. Proceeding - IEEE International Conference on Computing, Communication and Automation, ICCCA 2017, 2017-Janua, 864-869. https://doi.org/10.1109/CCAA.2017.8229928.

Stare, A. (2013). Agile Project Management - A Future Approach to the Management of Projects? Dynamic Relationships Management Journal, 2(1), 43-53. https://doi.org/10.17708/drmj.2013.v02n01a04.

Stare, A. (2014). Agile Project Management in Product Development Projects. Procedia - Social and Behavioral Sciences, 119, 295-304. https://doi.org/10.1016/j.sbspro.2014.03.034.

Streule, T., Miserini, N., Bartlomé, O., Klippel, M., \& de Soto, B. G. (2016). Implementation of Scrum in the Construction Industry. Procedia Engineering, 164, 269-276. https://doi.org/10.1016/j.proeng.2016.11.619.

Sverrisdottir, H. S., Ingason, H. T., \& Jonasson, H. I. (2014). The Role of the Product Owner in Scrum-comparison between Theory and Practices. Procedia - Social and Behavioral Sciences, 119, 257-267. https://doi.org/10.1016/j.sbspro.2014.03.030. 